\title{
Exploring Antiurolithic Effects of Gokshuradi Polyherbal Ayurvedic Formulation in Ethylene-Glycol-Induced Urolithic Rats
}

\author{
Amol L. Shirfule, ${ }^{1}$ Venkatesh Racharla, ${ }^{2}$ S. S. Y. H. Qadri, ${ }^{3}$ and Arjun L. Khandare ${ }^{1}$ \\ ${ }^{1}$ Food and Drug Toxicology Research Centre, National Institute of Nutrition, Hyderabad 500007, India \\ ${ }^{2}$ Department of Pharmacology, CMR College of Pharmacy, Hyderabad 500007, India \\ ${ }^{3}$ Pathology Division, National Institute of Nutrition, Hyderabad 500007, India \\ Correspondence should be addressed to Arjun L. Khandare; alkhandare@yahoo.com
}

Received 29 September 2012; Revised 20 December 2012; Accepted 27 December 2012

Academic Editor: Raffaele Capasso

Copyright ( 2013 Amol L. Shirfule et al. This is an open access article distributed under the Creative Commons Attribution License, which permits unrestricted use, distribution, and reproduction in any medium, provided the original work is properly cited.

Gokshuradi Yog $(G Y)$ is a polyherbal ayurvedic formulation used traditionally for several decades in India for the treatment of urolithiasis. The aim of the present study was to determine the underlying mechanism of $G Y$ action in the management of calcium oxalate urolithiasis. The effect of Gokshuradi polyherbal aqueous extracts (GPAEs) was studied on various biochemical parameters involved in calcium oxalate formation by employing in vitro and in vivo methods. GPAE exhibited significant antioxidant activity against 1, 1-diphenyl-2-picrylhydrazyl free radical and inhibited lipid peroxidation in the in vitro experiments. The rat model of urolithiasis induced by $0.75 \%$ ethylene glycol (EG) and $1 \%$ ammonium chloride (AC) in water caused polyuria, weight loss, impairment of renal function, and oxidative stress and decreased antioxidant enzyme activities in untreated control groups. However, GPAE- $(25,50$, and $100 \mathrm{mg} / \mathrm{kg})$ treated groups caused diuresis accompanied by a saluretic effect and revealed significant increase in antioxidant enzyme activities along with decreased oxalate synthesizing biochemical parameters at higher doses. This study revealed the antiurolithic effect of GPAE mediated possibly through inhibiting biochemical parameters involved in calcium oxalate formation, along with its diuretic and antioxidant effects, hence supporting its use in the treatment of calcium oxalate urolithiasis.

\section{Introduction}

Calcium oxalate urolithiasis has become a rising problem in many countries due to geographical/genetic variations and modern lifestyles. People living in drought and arid area suffer more from intestinal hyper absorption of calcium oxalate leading to kidney stones. It is estimated that $12 \%$ of the world population is affected by kidney stones with a recurrence rate from 70 to $80 \%$ in males and from 47 to $60 \%$ in females $[1,2]$. Calcium containing stones are the most common comprising about $75 \%$ of all urinary calculi, which are observed in the form of pure calcium oxalate $(50 \%)$ or calcium phosphate $(5 \%)$ and a mixture of both (45\%). Many factors affect the growth of urinary calculi in which mineral metabolism plays an important role [3].
The treatment modalities like surgery and drug therapy are practiced in the management of kidney stones but have some limitations. Surgical procedures like (extracorporeal shock wave lithotripsy) ESWL have increased risk of stone recurrence and are also not affordable to poor sufferers. The armamentarium of therapeutic agents also does not have any effective drugs except for some diuretics like thiazides and furosemide. This warranted a search for new drug therapy which will be cost effective and can target multiple etiological risk factors in urolithiasis. Ayurveda, a classical Indian authentic literature, reported the traditional use of Gokshuradi polyherbal formulation (GPF) and is being practiced since many years in the management of kidney stones. In our preliminary clinical studies, GPF has revealed expulsion of kidney stones in naturally occurred urolithic 
patients which was confirmed by X-ray analysis conducted before and after four weeks of treatment [4]. GPF consists of parts of five different medicinal plants that is, dry fruits of Tribulus terrestris L. seeds of Hygrophila spinosa T. Anders, and roots of Ricinnus communis L, Solanum anguivi Lamk. and Solanum surattense Burm. GPF decoction was prepared by mixing the fine powder of these individual parts at equal proportion as mentioned in the ayurvedic literature and then it was administered to the patients.

The individual component plants of GPF are known to possess various pharmacological activities. In Ayurvedic medicine, the fruits of $T$. terrestris $\mathrm{L}$. are recommended for the treatment of urinary disorders erectile dysfunction, and in traditional Chinese medicine, it has been used as an antihypertensive in coronary heart disease [5]. It also stimulates melanocyte proliferation and therefore is a putative treatment for Vitiligo along with its known antibacterial and cytotoxic activities [6,7]. H. spinosa T. Anders, another component of this formulation has been used in Ayurveda for various ailments like jaundice, hepatic obstruction, rheumatism, inflammation, pain, diuretic, and aphrodisiac and in the treatment of urinary disorders $[8,9]$. This plant is known to possess hypoglycemic activity in human subjects [10], antitumor [11], haematinic [12], antinociceptive [13], hepatoprotective $[14,15]$, free radical scavenging, and lipid peroxidation activities [16]. R. communis stems have anticancer, antidiabetic, and antiprotozoal activity [17]. Solanum anguivi (Lam.), also known as Solanum indicum sp. distichum (Schumach. and Thonn.), is cultivated for culinary purposes in many parts of Africa, India, and the Arab Peninsula. The fruits of this plant are used as nutritious vegetables on account of their high content of starch, calcium, vitamin A, ascorbic acid, and phosphate. Solanum xanthocarpum (SX) Schrad. \& Wendl. (Family: Solanaceae) is commonly known as the Indian night shade or Yellow berried night shade found throughout India, mostly in dry places as a weed along roadsides and waste lands [18]. It has held a place of some importance in the Indian Materia Medica, primarily as an expectorant and antipyretic. Various medicinal properties are attributed to it, particularly in the treatment of asthma, chronic cough, and catarrhal fever [19]. It is one of the members of the dashamula (ten roots) of the Ayurveda [20]. In Ayurveda, this plant is described as pungent, bitter, digestive, and alternative astringent. Its stems, flowers, and fruits are bitter, carminative. Root decoction is used as febrifuge, effective diuretic and expectorant [21].

Although, GPF is well recognized in Indian traditional medicine as having antiurolithic effect, but no scientific data have been published supporting its underlying mechanism of action on calcium oxalate stones. Therefore this study was proposed to determine the therapeutic potential and mechanism of action of aqueous extracts from this formulation in the management of urolithiasis by employing in vitro and in vivo methods.

\section{Material and Methods}

2.1. Chemicals and Reagents. All the were of analytical grade. Ethylene

chemicals used glycol, thymol, reduced glutathione, 5-5'-dithiobis, 2-nitrobenzoic acid, thiobarbituric acid, furosemide, $\mathrm{H}_{2} \mathrm{O}_{2}$, trichloroacetic acid, 1,1,3,3,-tetraethoxypropane, and guanidine hydrochloride were obtained from Sigma Chemical Company, St. Louis, MO, USA. Reagents used for histological preparations were eosin spirit soluble, hematoxylin, and xylene from Himedia Chemical Limited, Bombay, India. Kits used in this study for the determination of calcium, magnesium, blood urea nitrogen (BUN), creatinine, superoxide dismutase, glutathione peroxidase, oxalate, and citrate were purchased from Spinreact, Germany, and Ambika diagnostics, India.

2.2. Plant Materials. Plants used for the formulation were collected from local forests of Nanded District, Maharashtra, India, and authenticated by experts. Voucher specimens were deposited in the herbarium of the School of Life Sciences, S.R.T.M. University, Maharashtra, India. Respective parts of each plant as mentioned previously were collected and then shade dried. Dried parts were cleansed of extraneous matter and then grounded to fine powder in a grinder.

2.3. Standard Drug. Cystone polyherbal formulation from the Himalaya Drug Co., Bangalore, India was used as a standard drug in this study. The formulation contained Didymocarpus pedicellata, Saxifraga ligulata, Rubia cordifolia, Cyperus scariosus, Achyranthes aspera, Onosma bracteatum, Vernonia cinerea, purified Shilajeet, and Hajrul Yahood Bhasma.

2.4. In Vitro Antioxidant Effect. Antioxidant effect of GPAE was determined by free radical scavenging activity and lipid peroxidation inhibitory effects. $0.1 \mathrm{mM}$ solution of DPPH radical in methanol was prepared, and $1 \mathrm{~mL}$ of this solution was added to $3 \mathrm{~mL}$ of GPAE at different concentrations to determine the free radical scavenging activity [22]. Solutions were incubated for $30 \mathrm{~min}$ at room temperature, and then absorbance was measured at $517 \mathrm{~nm}$. Decrease in DPPH solution absorbance was considered as an increase of the $\mathrm{DPPH}$ radical-scavenging activity. This activity is given as $\% \mathrm{DPPH}$ radical scavenging which was calculated in the equation using DPPH solution as control.

Lipid peroxidation inhibitory activity was determined in the isolated rat kidneys which were electrically homogenized in ice cold $50 \mathrm{mM}$ phosphate buffer saline (PBS) and adjusted to $\mathrm{pH}$ 7.4. The homogenate was processed further, and lipid peroxidation inhibitory activity was determined by a reported method [23]. The inhibition ratio was calculated using the formula given for free radical scavenging activity.

\subsection{In Vivo Studies}

2.5.1. Animals. The animal care and handling was in accordance with the internationally accepted standard guidelines for use of animals, and the protocol was approved by institutional animal ethical committee (IAEC number P25/72011/GBR) at the National Institute of Nutrition, Hyderabad, India. Wistar rats (180-220 g) of either sex used for this study were sourced and housed at the National Centre for 
Laboratory Animal Sciences, Hyderabad, India, and kept in plastic cages $(47 \mathrm{~cm} \times 34 \mathrm{~cm} \times 18 \mathrm{~cm})$ with saw dust (renewed after every $48 \mathrm{~h}$ ), under a controlled temperature of $23-25^{\circ} \mathrm{C}$ and $12 \mathrm{~h}$ light-dark cycle. Animals were given standard rat chow diet available at the centre. Animals had free access to food and water ad libitum throughout the study except $24 \mathrm{~h}$ before and during $6 \mathrm{~h}$ of diuretic study, and while collecting $24 \mathrm{~h}$ urine samples, food was withdrawn.

\subsubsection{Preparation of GPAE and Cystone for Gastric Feeding.} Initially, GPF was prepared by mixing equally the respective parts of each plant at a ratio of $1: 1: 1: 1: 1$, respectively. In order to prepare the decoction for gastric gavages, $100 \mathrm{~g}$ of $G P F$ and $500 \mathrm{~mL}$ of doubly distilled (dd) water were heated in an autoclave for $15 \mathrm{~min}$ at $121^{\circ} \mathrm{C}$. After the boiling and sterilization procedure, the powder turned into a jelly-like paste which was dissolved in dd water to reach a final volume of $750 \mathrm{~mL}$. Then, the solution was stored at $4^{\circ} \mathrm{C}$ for 7 days. Subsequently, the solution was poured out and centrifuged at a rate of 1,500 rpm for $10 \mathrm{~min}$. Finally, the GPAE feeding solution containing $50 \mathrm{mg}$ of formulation per milliliter was prepared. The same procedure was performed for Cystone to make $100 \mathrm{mg}$ per milliliter of solution.

2.5.3. Diuretic Activity of GPAE. The diuretic activity of GPAE was studied on Wistar rats of either sex (180-220 g) as described previously [24]. Animals were divided with matched body weight and sex into groups of 6 animals each. Negative and standard drug control groups were given saline by gavage $(20 \mathrm{~mL} / \mathrm{kg})$ and Furosemide $(10 \mathrm{mg} / \mathrm{kg}$ of body weight), respectively. The rest of the groups were given different doses of the GPAE $(25,50$, and $100 \mathrm{mg} / \mathrm{kg})$ dissolved in saline. Subsequently, the animals were placed individually in metabolic and diuretic cages. The urine was collected, in graduated cylinders for $6 \mathrm{~h}$ at $1 \mathrm{~h}$ intervals. Total urine excreted out was collected and the volume was determined. The $\mathrm{pH}$ of the pooled urine from each animal was determined by using $\mathrm{pH}$ meter, $\mathrm{Na}^{+}$and $\mathrm{K}^{+}$concentrations on flame photometer, and $\mathrm{Ca}^{2+}$ concentration by using commercially available kits.

2.5.4. Effect of GPAE and Cystone on Animal Model of Urolithiasis. Antiurolithic activity of GPAE and Cystone was determined in an animal model of calcium oxalate urolithiasis as described by Atmani et al. [25]. The dose which had caused the significant increase in urine output in diuresis study was selected for this study. Twenty-four male Wistar rats (weighing 180-220 g) were divided with matched body weights into 5 groups of 6 animals each, which were then randomly selected to receive various treatments as follows.

Group I rats, served as vehicle-treated control, received intraperitoneal (i.p.) injections of normal saline $(2.5 \mathrm{~mL})$ once in $24 \mathrm{~h}$ and water ad libitum daily for 21 days (normal control).

Group II rats received stone-inducing treatment for 21 days, comprised of $0.75 \%$ (w/v) EG with $1 \%(w / v)$ ammonium chloride for 5 days; following this the water supply was switched to $0.75 \%$ EG alone in water, along with saline treatment (positive control urolithic group).

Group III rats received GPAE (50 mg/kg) through gastric gavages and simultaneously received stone-inducing treatment similar to the positive control daily for 21 days (treatment group, low dose).

Group IV rats received GPAE $(100 \mathrm{mg} / \mathrm{kg})$ through gastric gavages and simultaneously received stone-inducing treatment similar to the positive control daily for 21 days (treatment group, high dose).

Group V rats received standard drug-Cystone, $(100 \mathrm{mg} / \mathrm{kg})$ through gastric gavages and simultaneously received stone-inducing treatment similar to the positive control daily for 21 days (treatment group, standard drug).

2.5.5. Biochemical Examination. Immediately before and at the end of a total 21 days of treatment, $24 \mathrm{~h}$ urine samples were collected in the presence of a few thymol crystals, by housing animals individually in the metabolic and diuretic cages. Water intake was also determined simultaneously. Following volume and $\mathrm{pH}$ determination, part of each $24 \mathrm{~h}$ urine sample was acidified to $\mathrm{pH} 2$ with $5 \mathrm{MHCl}$. Both acidified and nonacidified urine samples were then centrifuged at $1500 \times \mathrm{g}$ for $10 \mathrm{~min}$ to remove debris and supernatants were stored at $-20^{\circ} \mathrm{C}$ until analyzed. In acidified urine samples, oxalate, calcium $\left(\mathrm{Ca}^{2+}\right)$ and magnesium $\left(\mathrm{Mg}^{2+}\right)$ contents were determined by using commercially available kits, while inorganic phosphate excretion was determined by reported method [26]. In nonacidified urine samples, citrate, creatinine, and uric acid, while in serum, creatinine and BUN were estimated with the help of kit-based methods.

Blood was collected through cardiac puncture from animals under ether anesthesia, and consequently both the kidneys and liver were excised. Animals were then sacrificed by $\mathrm{CO}_{2}$ inhalation.

2.5.6. Histopathological Examination. Organs were rinsed in ice cold physiological saline and weighed. The right kidney was fixed in $10 \%$ neutral buffered formalin, processed in series of graded alcohol and xylene, embedded in paraffin wax, sectioned at $5 \mu \mathrm{m}$, and stained with Haematoxylin and Eosin for examination under polarized light microscope. To count the number of crystalline deposits, a field of 100x was then randomly selected from each region, and calcium oxalate deposits were counted. The total number of deposits in each specimen was reported, and calcium content in kidney tissues was determined by atomic absorption spectrophotometer.

2.5.7. Lipid Peroxidation Inhibitory Effect. The left kidney was worked into $10 \%$ homogenate in PBS ( $50 \mathrm{mM}, \mathrm{pH} 7.4)$, centrifuged at $1500 \times \mathrm{g}$, and the supernatants were used to assess various antioxidant and oxalate forming enzymes activities and biochemical parameters like reduced glutathione (GSH), malondialdehyde (MDA), and protein carbonyl content.

Kidney homogenates were estimated for MDA content by thiobarbituric acid reactive method [27]. The protein carbonyl content was estimated by the protein derivatization with dinitrophenyl hydrazine (DNPH) into chromophoric 
TABLE 1: Diuretic effect of Gokshuradi polyherbal aqueous extracts (GPAEs).

\begin{tabular}{|c|c|c|c|c|c|}
\hline Groups & $\begin{array}{c}\text { Urine vol. } \\
(\mathrm{mL}) / 100 \mathrm{~g} \text { body } \\
\text { weight } / 6 \mathrm{~h}\end{array}$ & $\begin{array}{c}\mathrm{Na}^{+} \\
(\mathrm{mmol}) / 100 \mathrm{~g} \\
\text { body weight/6h }\end{array}$ & $\begin{array}{c}\mathrm{K}^{+} \\
(\mathrm{mmol}) / 100 \mathrm{~g} \\
\text { body weight } / 6 \mathrm{~h}\end{array}$ & $\begin{array}{c}\mathrm{Ca}^{2+} \\
(\mathrm{mmol}) / 100 \mathrm{~g} \\
\text { body weight } / 6 \mathrm{~h}\end{array}$ & $\mathrm{pH}$ \\
\hline Control & $0.59 \pm 0.14$ & $0.09 \pm 0.03$ & $0.10 \pm 0.02$ & $7.82 \pm 1.62$ & $5.87 \pm 0.06$ \\
\hline GPAE $25 \mathrm{mg} / \mathrm{kg}$ & $1.23 \pm 0.21$ & $0.13 \pm 0.01$ & $0.15 \pm 0.02$ & $6.22 \pm 2.29$ & $6.85 \pm 0.05$ \\
\hline GPAE $50 \mathrm{mg} / \mathrm{kg}$ & $1.51^{*} \pm 0.18$ & $0.19 \pm 0.01$ & $0.19 \pm 0.05$ & $3.69 \pm 1.76$ & $6.93 \pm 0.18$ \\
\hline GPAE $100 \mathrm{mg} / \mathrm{kg}$ & $1.72^{* *} \pm 0.11$ & $0.26^{*} \pm 0.02$ & $0.22^{*} \pm 0.03$ & $2.37^{*} \pm 1.33$ & $7.32^{* *} \pm 0.24$ \\
\hline Furosemide $10 \mathrm{mg} / \mathrm{kg}$ & $2.10^{* *} \pm 0.31$ & $0.38^{* *} \pm 0.07$ & $0.21^{* *} \pm 0.02$ & $1.26^{*} \pm 0.49$ & $7.39^{* *} \pm 0.27$ \\
\hline
\end{tabular}

Values given are mean \pm S.E.M. $(n=6)$.

${ }^{*} P<0.05$.

${ }^{* *} P<0.01$ versus control

TABLE 2: Effect of GPAE and standard drug on $24 \mathrm{~h}$ urinary biochemical parameters.

\begin{tabular}{lccccc}
\hline Parameters & Control & Urolithic & GPAE 50 mg/kg & GPAE 100 mg & Standard drug 100 mg/kg \\
\hline Change in body weight (\%) & $11.88 \pm 1.53$ & $-4.78^{* *} \pm 1.08$ & $2.32^{* *, \# \#} \pm 1.45$ & $8.86^{\# \#} \pm 2.06$ & $5.43^{* *, \# \#} \pm 1.23$ \\
Water intake $\mathrm{mL} / 24 \mathrm{~h}$ & $6.22 \pm 0.39$ & $24.35^{* *} \pm 7.23$ & $14.3 \pm 2.32$ & $8.45^{\#} \pm 1.17$ & $11.2 \pm 2.21$ \\
Urine vol. $(\mathrm{mL})$ & $5.82 \pm 0.45$ & $26.25^{* *} \pm 6.76$ & $16.43^{*} \pm 3.24$ & $10.46^{*, \# \pm 1.26}$ & $13.65^{*} \pm 2.84$ \\
pH & $6.38 \pm 0.09$ & $6.17 \pm 0.16$ & $6.27 \pm 0.11$ & $6.45 \pm 0.14$ & $6.32 \pm 0.15$ \\
Oxalate (mg) & $0.38 \pm 0.10$ & $2.12^{* *} \pm 0.21$ & $1.35^{* *} \pm 0.25$ & $0.68^{\# \# \pm 0.11}$ & $1.89^{* *} \pm 0.18$ \\
$\mathrm{Ca}^{2+}(\mathrm{mg})$ & $3.67 \pm 0.24$ & $1.84^{* *} \pm 0.16$ & $2.63^{*} \pm 0.29$ & $3.16^{\#} \pm 0.64$ & $2.89^{*} \pm 0.41$ \\
$\mathrm{Mg}^{2+}(\mathrm{mg})$ & $3.28 \pm 0.32$ & $2.67 \pm 0.11$ & $3.42 \pm 0.24$ & $3.76^{\#} \pm 0.31$ & $2.87 \pm 0.32$ \\
Citrate (mg) & $23.10 \pm 1.21$ & $18.5 \pm 1.90$ & $19.12 \pm 2.63$ & $19.31 \pm 1.22$ & $18.34 \pm 2.54$ \\
$\mathrm{IP}(\mathrm{mg})$ & $6.26 \pm 0.82$ & $7.89 \pm 1.25$ & $7.57 \pm 0.55$ & $7.55 \pm 0.75$ & $7.34 \pm 0.32$ \\
$\mathrm{UA}^{\mathrm{b}}(\mathrm{mg})$ & $0.58 \pm 0.17$ & $1.23 \pm 0.40$ & $1.05 \pm 0.25$ & $0.83 \pm 0.22$ & $0.98 \pm 0.22$ \\
\hline
\end{tabular}

Values given are mean \pm S.E.M. $(n=6)$.

${ }^{*} P<0.05$

${ }^{* *} P<0.01$ versus control group.

${ }^{\#} P<0.05$

\#\# $P<0.01$ versus urolithic group.

${ }^{\mathrm{a}}$ Inorganic phosphate. ${ }^{\mathrm{b}}$ Uric acid.

dinitrophenyl hydrazones by the method of Levine et al. [28], and the carbonyl content was calculated using the DNPH molar extinction coefficient of $22,000 \mathrm{M}^{-1} \mathrm{~cm}^{-1}$. GSH was estimated as total nonprotein thiol ( $\mathrm{SH}$ ) group following the method described by Moron et al. [29]. Superoxide dismutase (SOD) and glutathione peroxidase (GPx) were determined by using commercially available kits. Catalase activity was determined by monitoring the decomposition of $\mathrm{H}_{2} \mathrm{O}_{2}$ at $240 \mathrm{~nm}$ with a spectrophotometer [30]. Catalase activity was calculated by using $\varepsilon_{240}$ (molar extinction coefficient) $=0.0394 \mathrm{mmol}^{-1} \mathrm{~min}^{-1}$ for $\mathrm{H}_{2} \mathrm{O}_{2}$ and expressed as $\mu$ moles of $\mathrm{H}_{2} \mathrm{O}_{2}$ decomposed per min under standard conditions at $25^{\circ} \mathrm{C}$. Glycolate oxidase (GOx) activity in liver and lactate dehydrogenase $(\mathrm{LDH})$ in both liver and kidney were determined by reported method $[31,32]$.

2.5.8. Statistical Analysis. The data expressed are mean \pm standard error of mean (S.E.M.) and the median inhibitory concentration ( $\mathrm{IC}_{50}$ value) with $95 \%$ confidence intervals. All statistical comparisons between the groups are made by means of one way analysis of variance with post hoc Student's $t$-test. The $P$ values less than 0.05 are regarded as significant. The concentration-response curves were analyzed by nonlinear regression using Graph Pad Prism (Graph Pad Software, San Diego, CA, USA).

\section{Result}

\subsection{In Vitro Studies}

3.1.1. Antioxidant Effect. GPAE revealed DPPH radical scavenging activity with $\mathrm{IC}_{50}$ value of $2.5(1.05-2.90) \mu \mathrm{g} / \mathrm{mL}$ (Figure 1(a)) and inhibited lipid peroxidation of the rat kidney homogenate in vitro by $36.37 \pm 1.86$ and $68.72 \pm$ $0.25 \%$ at 50 and $150 \mu \mathrm{g} / \mathrm{mL}$, respectively (Figure $1(\mathrm{~b})$ ). The standard chemical, BHT, similarly showed DPPH radical scavenging activity with $\mathrm{IC}_{50}$ value of $2.56(1.02-2.85) \mu \mathrm{g} / \mathrm{mL}$ and inhibited in vitro lipid peroxidation by $38.4 \pm 1.22$ and $94.5 \pm 4.6 \%$ at 50 and $150 \mu \mathrm{g} / \mathrm{mL}$, respectively.

\subsection{In Vivo Studies}

3.2.1. Diuretic Effect. The effect of various doses of GPAE on rat urine volume, $\mathrm{pH}$, and $\mathrm{Na}^{+}, \mathrm{K}^{+}$, and $\mathrm{Ca}^{2+}$ excretion is given in Table 1. GPAE increased urine volume at $50 \mathrm{mg} / \mathrm{kg}$ $(P<0.05)$ and $100 \mathrm{mg} / \mathrm{kg}(P<0.01)$ indicating diuretic 
TABLE 3: Effect of GPAE and standard drug on serum parameters.

\begin{tabular}{lccccc}
\hline Parameters & Control & Urolithic & GPAE 50 mg/kg & GPAE $100 \mathrm{mg}$ & Standard drug $100 \mathrm{mg} / \mathrm{kg}$ \\
\hline $\mathrm{SC}^{\mathrm{c}}(\mathrm{mg} / \mathrm{dL})$ & $0.86 \pm 0.05$ & $1.43^{* *} \pm 0.12$ & $1.26 \pm 0.16$ & $0.89^{\#} \pm 0.10$ & $1.08 \pm 0.12$ \\
$\mathrm{CC}^{\mathrm{d}}(\mathrm{mg} / \mathrm{min})$ & $0.86 \pm 0.06$ & $0.50^{* *} \pm 0.06$ & $0.64 \pm 0.10$ & $0.85^{\# \#} \pm 0.07$ & $0.72 \pm 0.12$ \\
$\mathrm{BUN}^{\mathrm{e}}(\mathrm{mg} / \mathrm{dL})$ & $19.89 \pm 1.40$ & $57.04^{* *} \pm 12.46$ & $46.3 \pm 11.40$ & $20.5^{\# \#} \pm 1.08$ & $36.2 \pm 10.20$ \\
\hline
\end{tabular}

Values given are mean \pm S.E.M. $(n=6)$.

${ }^{*} P<0.05$.

${ }^{* *} P<0.01$ versus control group.

${ }^{\#} P<0.05$.

${ }^{\# \#} P<0.01$ versus urolithic group.

${ }^{\mathrm{c}}$ Serum creatinine. ${ }^{\mathrm{d}}$ Creatinine clearance. ${ }^{\mathrm{e}}$ Blood urea nitrogen.

TABLE 4: Effect of GPAE and standard drug on kidney and liver parameters.

\begin{tabular}{lccccc}
\hline Parameters & Control & Urolithic & GPAE 50 mg/kg & GPAE 100 mg & Standard drug 100 mg/kg \\
\hline Kidney weight (g) & $0.78 \pm 0.05$ & $1.21^{* *} \pm 0.12$ & $1.09^{*} \pm 0.14$ & $0.82^{\#} \pm 0.07$ & $0.98^{*} \pm 0.12$ \\
$\mathrm{CD}^{\mathrm{f}}$ & Absent & Significant & Moderate & Not significant & Moderate \\
$\mathrm{MDA}^{\mathrm{g}}(\mathrm{nmol})$ & $0.64 \pm 0.14$ & $6.52^{* *} \pm 0.85$ & $3.06 \pm 1.10$ & $1.09^{\# \#} \pm 0.42$ & $2.85 \pm 1.08$ \\
$\mathrm{PCC}^{\mathrm{h}}(\mathrm{nmol})$ & $5.08 \pm 0.68$ & $13.04^{* *} \pm 1.36$ & $10.12 \pm 1.88$ & $8.05^{\#} \pm 1.14$ & $9.80 \pm 1.23$ \\
$\mathrm{GSH}^{\mathrm{i}}(\mathrm{nmol})$ & $17.89 \pm 0.98$ & $13.10^{*} \pm 1.33$ & $15.03 \pm 1.82$ & $16.98^{\#} \pm 1.57$ & $14.02 \pm 1.31$ \\
$\mathrm{SOD}^{\mathrm{j}}(\mathrm{U})$ & $6.22 \pm 0.84$ & $3.01^{* *} \pm 0.29$ & $4.58 \pm 0.32$ & $5.48^{\#} \pm 0.56$ & $4.21 \pm 0.21$ \\
$\mathrm{GPX}^{\mathrm{k}}(\mathrm{U})$ & $0.58 \pm 0.05$ & $0.32^{*} \pm 0.04$ & $0.47 \pm 0.08$ & $0.53^{\#} \pm 0.07$ & $0.48 \pm 0.05$ \\
$\mathrm{Cat}^{1}\left(\mu \mathrm{MH} \mathrm{O}_{2} / \mathrm{min}\right)$ & $32.89 \pm 2.55$ & $16.89^{* *} \pm 1.98$ & $20.92 \pm 5.11$ & $24.90 \pm 2.32$ & $21.08 \pm 4.32$ \\
$\mathrm{GOx}^{\mathrm{m}}(\mathrm{nmol} / \mathrm{mg})$ & $1.61 \pm 0.07$ & $2.35 \pm 0.06^{* *}$ & $1.77 \pm 0.17$ & $1.50 \pm 0.10^{\#}$ & $1.65 \pm 0.17$ \\
$\mathrm{LDH}^{\mathrm{n}}(\mathrm{U} / \mathrm{mg})(\mathrm{Liver})$ & $1.54 \pm 0.06$ & $4.03 \pm 0.09^{* *}$ & $1.49 \pm 1.08$ & $1.51 \pm 0.06^{\#}$ & $1.46 \pm 1.04$ \\
$\mathrm{LDH}^{\mathrm{o}}(\mathrm{U} / \mathrm{mg})($ Kidney) & $2.82 \pm 0.16$ & $4.68 \pm 0.19^{* *}$ & $3.19 \pm 1.08$ & $3.07 \pm 1.08^{\#}$ & $3.32 \pm 1.04$ \\
$\mathrm{Calcium}^{\mathrm{p}}(\mathrm{mg} / \mathrm{g})($ Kidney) & $0.292 \pm 0.16$ & $0.498 \pm 0.082$ & $0.375 \pm 0.078$ & $0.316 \pm 0.021^{\# \#}$ & $0.369 \pm 0.038^{\#}$ \\
\hline
\end{tabular}

Values given are mean \pm S.E.M. $(n=6) .{ }^{*} P<0.05 .{ }^{* *} P<0.01$ versus control group. ${ }^{*} P<0.05 .{ }^{\# \#} P<0.01$ versus urolithic group.

${ }^{\mathrm{f}}$ Crystal deposits/100x: field, ${ }^{\mathrm{g}}$ malondialdehyde, ${ }^{\mathrm{h}}$ protein carbonyl content, ${ }^{\mathrm{i}}$ reduced glutathione, ${ }^{\mathrm{j}}$ superoxide dismutase, ${ }^{\mathrm{k}}$ glutathione peroxidase, ${ }^{1}$ catalase, ${ }^{\mathrm{m}}$ glycolate oxidase (nmol of glyoxylate formed/mg protein), ${ }^{\mathrm{n}}$ liver lactate dehydrogenase (U/mg protein), ${ }^{\mathrm{o}}$ kidney lactate dehydrogenase (U/mg protein), and ${ }^{\mathrm{p}}$ kidney calcium content.

effect. At the next higher dose $(200 \mathrm{mg} / \mathrm{kg})$, urine volume did not increase above that of saline-treated group $(P>$ 0.05). The reference diuretic drug, Furosemide at $10 \mathrm{mg} / \mathrm{kg}$, showed statistically significant increase in the urine output $(P<0.01)$. In addition to an increase in the urine output, $G P A E$, and similarly Furosemide, increased urine excretion of $\mathrm{Na}^{+}$and $\mathrm{K}^{+}$compared to the saline-treated control animals at higher dose. GPAE caused significant increase in the urine $\mathrm{pH}$ and decrease in $\mathrm{Ca}^{2+}$ excretion $(P<0.01)$ at $100 \mathrm{mg} / \mathrm{kg}$ comparable to the standard drug, Furosemide $(10 \mathrm{mg} / \mathrm{kg})$.

3.2.2. Effect Observed in the Animal Model. The baseline parameters recorded before the start of treatment like body weights, water intake along with urine volume, $\mathrm{pH}$, and composition were not significantly different among all the groups. The parameters recorded after the treatment are given in Table 2. As compared to normal control animals, water intake and $24 \mathrm{~h}$ urine volume were high in the urolithic group $(P<0.01)$. Stone-inducing treatment also reduced $\mathrm{pH}$ of urine in the urolithic group as compared to that of the normal control group, although not to a significant extent. Simultaneous treatment with GPAE at $100 \mathrm{mg} / \mathrm{kg}$ in treatment groups reduced the increase in urine volume and water intake $(P<0.05)$ as compared with the control animals $(P<0.05)$. There was an increased oxalate and decreased
$\mathrm{Ca}^{2+}$ concentration $(P<0.01)$ of the urine collected from the urolithic animals as compared to normal control. GPAE and Cystone groups exactly reversed this effect, that is, decreased the urinary oxalate $(P<0.01)$ and increased $\mathrm{Ca}^{2+}(P<0.05)$ excretion at all the treated doses and remained significant at $100 \mathrm{mg} / \mathrm{kg}$ in GPAE-treated group. Other changes in the urine composition like decreased levels of citrate and $\mathrm{Mg}^{2+}$ and increased excretion of uric acid and inorganic phosphate in urolithic group were not statistically significant. GPAEand Cystone-treated groups also did not show any statistically significant change in these parameters and remained comparable to that of control animals. The urolithic treatment revealed loss in body weight of the urolithic animals $(P<$ 0.01 ), whereas GPAE- and Cystone-treated animals showed net gain in the body weights at all the tested doses. Kidneys of urolithic group animals were heavier than those the control animals $(P<0.01)$, whereas GPAE- $(100 \mathrm{mg} / \mathrm{kg})$ treated rat kidneys did not show any significant increase in weight as compared with control; however the GPAE- $(50 \mathrm{mg} / \mathrm{kg})$ and Cystone- $(100 \mathrm{mg} / \mathrm{kg})$ treated animal's kidneys were slightly heavier than those the control animals (Table 4).

Urolithic treatment was found to disturb renal function in urolithic animals as evident from the increased BUN and serum creatinine and reduced creatinine clearance. GPAEtreated groups decreased the serum creatinine and BUN 


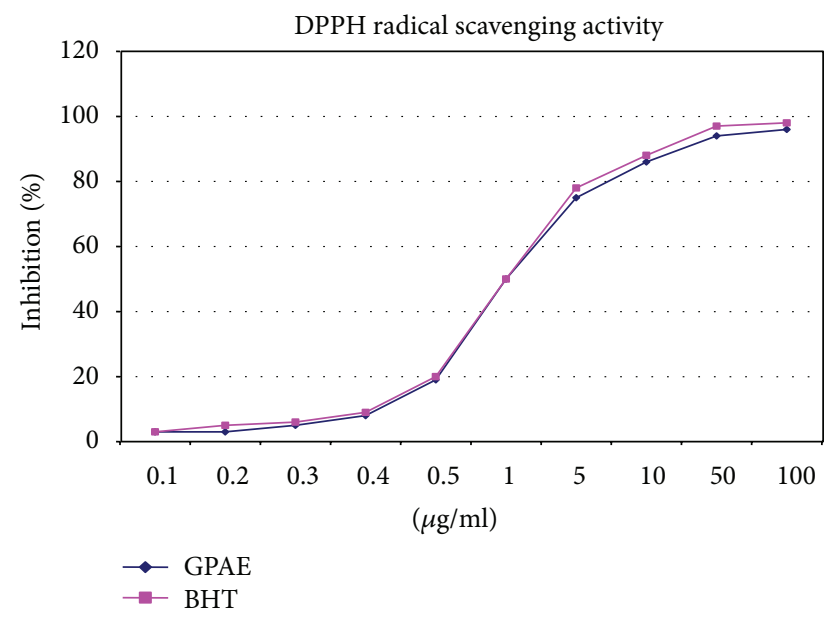

(a)

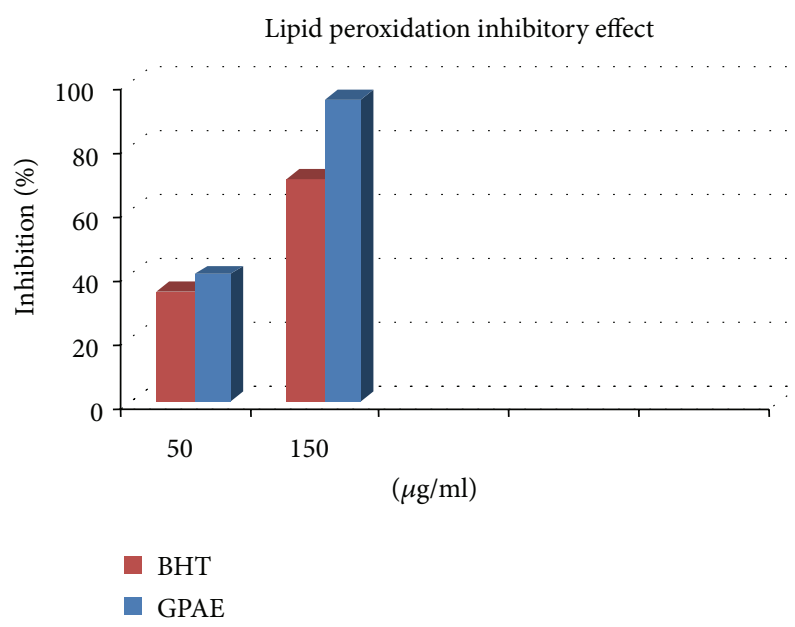

(b)

FIGURE 1: (a) DPPH radical scavenging activity. (b) Lipid peroxidation inhibitory effect of GPAE and the reference drug butylated hydroxytoluene (BHT). Symbols shown are mean \pm S.E.M. $(n=3)$.

levels at $100 \mathrm{mg} / \mathrm{kg}$, and similar observations were made in the Cystone-treated groups at $100 \mathrm{mg} / \mathrm{kg}$ as compared to control. The creatinine clearance was significantly increased at $100 \mathrm{mg} / \mathrm{kg}$ in GPAE-treated groups as compared to urolithic animals but was not significant at $50 \mathrm{mg} / \mathrm{kg}$ (Table 3 ).

Histology studies of the kidney regions like cortex, medulla, and papilla in the urolithic animals showed many birefringent crystalline deposits under polarized light microscope (Figure 2(b)). Such deposits were found in 3 out of 6 rats from GPAE low dose (Figure 2(c)), 1 out of 6 rats from GPAE high dose (Figure 2(d)), and 3 out of 6 rats (Figure 2(e)) from Cystone group but visibly smaller and less abundant compared to urolithic control animals. The tissue morphology and intactness of the kidneys of GPAE- and Cystone-treated groups were comparable to the normal control animals (Figure 2(a)). The atomic absorption spectrophotometer analysis revealed decreased $\mathrm{Ca}$ content in the GPAE- and Cystone- $(P<0.05)$ treated groups as compared with the urolithic control groups wherein the
GPAE at $100 \mathrm{mg} / \mathrm{kg}$ shown significant decrease of $\mathrm{Ca}(P<$ 0.01) (Table 4).

3.2.3. Lipid Peroxidation Inhibitory Effect. Stone-inducing treatment increased MDA and carbonyl protein content $(P<$ $0.01)$ and decreased GSH level $(P<0.05)$ and activities of the antioxidant enzymes including SOD $(P<0.01)$, GPX $(P<0.05)$, and catalase $(P<0.01)$ in kidneys of the urolithic rats as compared to control animals. Activities of oxalate forming enzymes including GOx $(P<0.01)$ in liver and LDH $(P<0.01)$ in both liver and kidneys were found to be enhanced in urolithic group compared to control animals whereas treatment with GPAE was found to be protective against this effect and oxidative changes induced by urolithic treatment at higher doses (Table 4, Figure 1(b)).

\section{Discussion}

Phytotherapy approach is attempted in this study as an alternative to primary healthcare. The Gokshuradi Polyherbal Formulation (GPF) which is traditionally being utilized in Indian folk medicine since several decades to treat kidney stones was evaluated for its antiurolithic effects. In our earlier studies, we have clinically evaluated the efficacy of this preparation and found its potential in naturally induced urolithic patients [4]. The present study is a reverse pharmacology approach wherein the scientific studies were undertaken under controlled conditions to validate the traditional use of GPF and determine its underlying mechanism of action on calcium oxalate urolithiasis.

Calcium oxalate stone development is a multifactorial process involving various etiological factors. Studies have shown that calcium oxalate crystal deposition leads to the cellular injury mediated by lipid peroxidation through free oxygen radical generation. Studies revealed that these cellular injuries favor the events of calcium oxalate retention in renal tubules which is significant for further stone development [33-35]. Recent clinical data are also supporting this finding that formation of urinary stones leads to the oxidative stress in patients [36]. Antioxidants such as vitamin C, catechin, and selenium have proved to be protective against such oxidative injury due to calcium oxalate crystal deposition as evidenced from various experimental studies [37-39]. In this regard, antioxidant potential of GPAE was determined by free radical scavenging and lipid peroxidation inhibitory activity to study its mechanism of action. Interestingly, GPAE revealed DPPH free radical scavenging and inhibited lipid peroxidation of rat kidney homogenate similar to a standard antioxidant chemical, BHT.

In the diuretic activity study, GPAE altered urine output in a dose dependant manner and maximum diuresis observed at $100 \mathrm{mg} / \mathrm{kg}$. At next higher dose that is, $200 \mathrm{mg} / \mathrm{kg}$, it did not lead to any further increase in the urine volume and remained comparable to the normal control group. The disappearance of the diuretic effect of these polyherbal extracts at this higher dose is not completely understood. Increase in urine volume by GPAE was also associated with the increase in $\mathrm{Na}^{+}$and $\mathrm{K}^{+}$ electrolyte loss similar to the standard diuretic furosemide. 


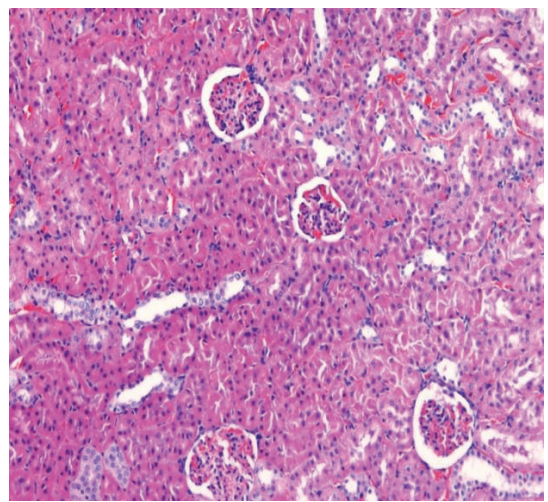

(a)

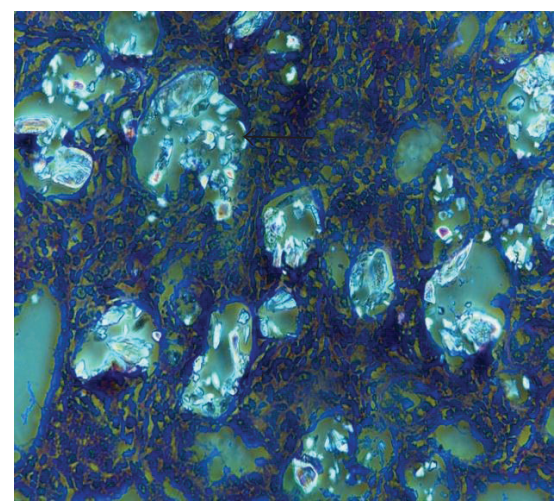

(b)

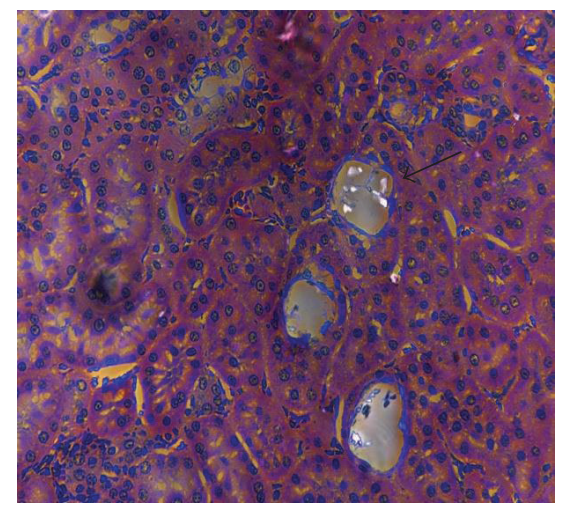

(c)

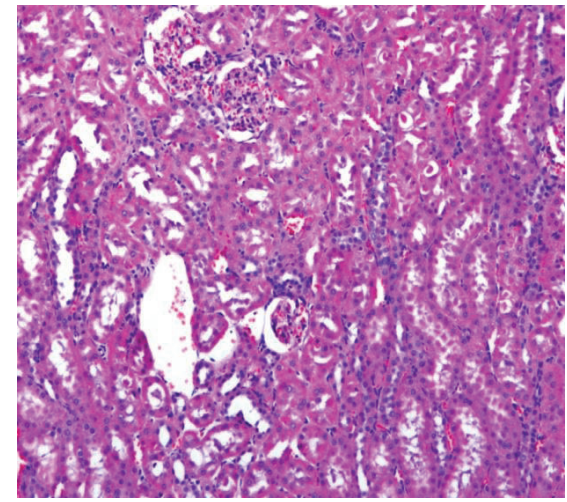

(d)

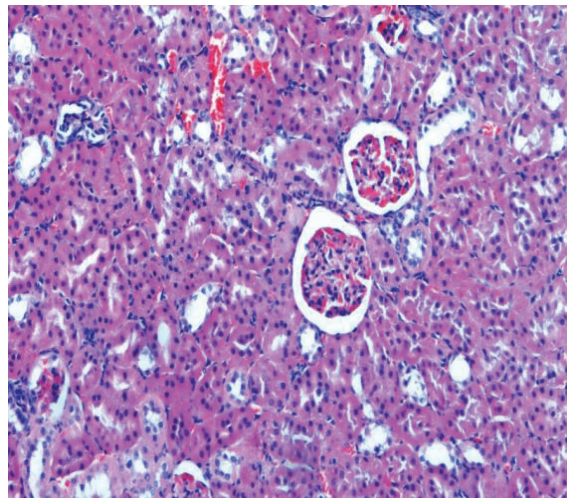

(e)

FIGURE 2: (a) Normal cellular structure of control rats kidney (Gr I). (b) Ethylene-glycol-induced urolithic rats kidney showing irregular crystals dilation and inflammation under polarized microscope (Gr II). (c) Kidneys of urolithic rats treated with GPAE (50 mg/kg) showing near normal cellular structure under polarized microscope (Gr III). (d) Kidneys of urolithic rats treated with GPAE (100 mg/kg) showing normal cellular Structure (Gr IV). (e) Kidneys of urolithic rats treated with Cystone (100 mg/kg) showing normal cellular Structure (Gr. V). Arrow indicates $\mathrm{CaOx}$ crystals.

Increase in urine volume, thus suggestive of possible loss of these electrolytes leading to this effect. GPAE-treated group is also revealed increase in urine $\mathrm{pH}$ and decrease in urine $\mathrm{Ca}^{2+}$ at $100 \mathrm{mg} / \mathrm{kg}$ like that of furosemide-treated groups. These hypocalciuric and diuretic effects of GPAE may help to reduce urinary super saturation of calcium salts and thus can prevent further stone formation.

Further antiurolithic effect of GPAE was evaluated in an animal model of urolithiasis induced by ethylene glycol and ammonium chloride in combination. This model is frequently used in calcium oxalate stone formation and therefore was selected for this study [25, 40, 41]. After 21 days, administration of EG +AC showed larger and aggregated crystals in urolithic control animals compared to the GPAEand Cystone-treated groups. These calcium oxalate crystal agglomerates get deposited in the renal tubules and further develop into renal stones [25]. GPAE reduced the polyuria associated with lithogenic treatment as compared to urolithic control groups. As per the earlier reports, stone induction treatment leads an increase in oxalate and decrease in $\mathrm{Ca}^{2+}$ excretion. This is confirmed in the present study in which urolithic control animals showed the similar effect, and GPAE- and Cystone-treated groups reversed this effect [42, 43].

Lithogenic treatment resulted in increased calcium oxalate deposition in the urolithic control groups along with oxidative stress determined from increased levels of markers of oxidative damage, that is, MDA and protein carbonyl content, along with decreased activity of antioxidant enzymes and GSH levels in kidneys accompanied with abnormal renal function. The renal tubules were dilated in entire kidneys of all untreated rats leading to disturbed renal flow by large crystal aggregates. However, GPAE revealed significant decrease in all these lithogenic markers at higher doses along with the antioxidant activity.

The present investigation thus reports the significant antiurolithic potential of GPAE at higher doses by the combination of antioxidant, diuretic, and hypocalciuric effects. The results of the formulation were found significant as compared with Cystone which is a standard drug available in the market 
used in the treatment of urolithiasis, and diuretic activity was comparable with the standard diuretic drug, Furosemide.

\section{Conclusions}

The inhibitory effect of GPAE on calcium oxalate crystal retention in renal tubules thus can be attributed to its diuretic, hypocalciuric, antioxidant effect along with its potential to inhibit biochemical parameters involved in oxalate metabolism which rationalize its medicinal use for urinary stone disease. The present study will certainly benefit the scientific community worldwide in providing a source for isolation and designing a molecule in this research pipeline.

\section{Acknowledgments}

The authors are thankful to The Indian Council of Medical Research (ICMR), New Delhi, for financial assistance to this postdoctoral project and, Director the National Institute of Nutrition, Hyderabad, for providing necessary laboratory facilities.

\section{References}

[1] G. C. Curhan, W. C. Willett, E. B. Rimm, and M. J. Stampfer, "A prospective study of the intake of vitamins $\mathrm{C}$ and $\mathrm{B} 6$, and the risk of kidney stones in men," Journal of Urology, vol. 155, no. 6, pp. 1847-1851, 1996.

[2] C. L. Smith and D. R. P. Guay, "Nephrolithiasis," in Pharmacotherapy and Pathophysiologic Approach, J. T. Di Piro, R. L. Talbert, P. E. Hayes, G. C. Yee, G. R. Matzke, and L. M. Posey, Eds., pp. 720-736, Elsevier, New York, NY, USA, 2nd edition, 1992.

[3] F. L. Coe and M. J. Favus, Disorders of Bone and Mineral Metabolism, Raven press, New York, NY, USA, 1992.

[4] A. L. Shirfule, C. N. Khobragade, P. Badrinarayan, Y. S. Borse, and R. H. Amilkanthwar, "Phytochemical analysis and antiurolithiatic activity of a polyherbal formulation," Journal of Herbs, Spices and Medicinal Plants, vol. 15, no. 1, pp. 66-72, 2009.

[5] A. M. Sharifi, R. Darabi, and N. Akbarloo, "Study of antihypertensive mechanism of Tribulus terrestris in 2K1C hypertensive rats: role of tissue ACE activity," Life Sciences, vol. 73, no. 23, pp. 2963-2971, 2003.

[6] R. C. Singh and C. S. Sisodia, "Effect of Tribulus terrestris fruit extracts on chloride and creatinine renal clearances in dogs," Indian Journal of Physiology and Pharmacology, vol. 15, no. 3, pp. 93-96, 1971.

[7] M. Al-Ali, S. Wahbi, H. Twaij, and A. Al-Badr, "Tribulus terrestris: preliminary study of its diuretic and contractile effects and comparison with Zea mays," Journal of Ethnopharmacology, vol. 85, no. 2-3, pp. 257-260, 2003.

[8] A. K. Nadkarni, Indian Materia Medica, vol. 1, Popular Book Depot, Bombay, India, 3rd edition, 1976.

[9] R. N. Chopra, S. L. Nayar, and I. C. Chopra, Glossary of Indian Medicinal Plants, CSIR, New Delhi, India, 1956.

[10] M. R. Fernando, S. M. D. N. Wickramasinghe, M. I. Thabrew, and E. H. Karunanayaka, "A preliminary investigation of the possible hypoglycaemic activity of Asteracanthus longifolia," Journal of Ethnopharmacology, vol. 27, no. 1-2, pp. 7-14, 1989.
[11] U. K. Mazumdar, M. Gupta, S. Maiti, and D. Mukherjee, "Antitumor activity of Hygrophila spinosa on Ehrlich ascites carcinoma and sarcoma-180 induced mice," Indian Journal of Experimental Biology, vol. 35, no. 5, pp. 473-477, 1997.

[12] A. Gomes, M. Das, and S. C. Dasgupta, "Haematinic effect of Hygrophila spinosa T. Anderson on experimental rodents," Indian Journal of Experimental Biology, vol. 39, no. 4, pp. 381382, 2001.

[13] P. Shanmugasundaram and S. Venkataraman, "Anti-nociceptive activity of Hygrophila auriculata (Schum) Heine," The African Journal of Traditional, Complementary and Alternative Medicines, vol. 2, p. 62, 2005.

[14] A. Singh and S. S. Handa, "Hepatoprotective activity of Apium graveolens and Hygrophila auriculata against paracetamol and thioacetamide intoxication in rats," Journal of Ethnopharmacology, vol. 49, no. 3, pp. 119-126, 1995.

[15] P. Shanmugasundaram and S. Venkataraman, "Hepatoprotective and antioxidant effects of Hygrophila auriculata (K. Schum) Heine Acanthaceae root extract," Journal of Ethnopharmacology, vol. 104, no. 1-2, pp. 124-128, 2006.

[16] M. Vijayakumar, R. Govindarajan, G. M. M. Rao et al., "Action of Hygrophila auriculata against streptozotocin-induced oxidative stress," Journal of Ethnopharmacology, vol. 104, no. 3, pp. 356-361, 2006.

[17] Z. A. Ali and V. K. Singh, "Herbal drugs of Himalaya (medicinal plants of Garhwal and Kumaon regions of India)," in Aspect of Plant Sciences, vol. 15, pp. 110-111, Today \& Tomorrow's Printers, New Delhi, India, 1998.

[18] Anonymous, in The Wealth of India-Raw Materials, pp. 393-394, Council of Scientific and Industrial Research, New Delhi, India, 1989.

[19] S. Siddiqui, S. Faizi, and B. Siddiqui, "Studies in the chemical constituents of the fresh berries of Solanum xanthocarpum," Journal of the Chemical Society of Pakistan, vol. 5, no. 2, pp. 1421, 1983.

[20] L. Mohan, P. Sharma, and C. N. Srivastava, "Comparative efficacy of Solanum xanthocarpum extracts alone and in combination with a synthetic pyrethroid, cypermethrin, against malaria vector, Anopheles Stephensi," Southeast Asian Journal of Tropical Medicine and Public Health, vol. 38, no. 2, pp. 256260, 2007.

[21] G. P. Vadnere, R. S. Gaud, and A. K. Singhai, "Evaluation of antiasthmatic property of Solanum Xanthocarpum flower extracts," Pharmacologyonline, vol. 1, pp. 513-522, 2008.

[22] D. J. Huang, C. D. Lin, H. J. Chen, and Y. H. Lin, "Antioxidant and antiproliferative activities of sweet potato (Ipomea batata [L.] Lam 'Taniong 57') constituents," Botanical Bulletin of Academia Sinica, vol. 45, pp. 179-186, 2004.

[23] D. G. Kang, C. K. Yun, and H. S. Lee, "Screening and comparison of antioxidant activity of solvent extracts of herbal medicines used in Korea," Journal of Ethnopharmacology, vol. 87, no. 2-3, pp. 231-236, 2003.

[24] A. E. Consolini, O. A. N. Baldini, and A. G. Amat, "Pharmacological basis for the empirical use of Eugenia uniflora L. (Myrtaceae) as antihypertensive," Journal of Ethnopharmacology, vol. 66, no. 1, pp. 33-39, 1999.

[25] F. Atmani, Y. Slimani, M. Mimouni, and B. Hacht, "Prophylaxis of calcium oxalate stones by Herniaria hirsuta on experimentally induced nephrolithiasis in rats," British Journal of Urology International, vol. 92, no. 1, pp. 137-140, 2003. 
26] J. A. Daly and G. Ertingshausen, "Direct method for determining inorganic phosphate in serum with the "centrifichem," Clinical Chemistry, vol. 18, pp. 263-265, 1972.

[27] S. H. Y. Wong, J. A. Knight, S. M. Hopfer, O. Zaharia, C. N. Leach Jr., and F. W. Sunderman Jr., "Lipoperoxides in plasma as measured by liquid-chromatographic separation of malondialdehyde-thiobarbituric acid adduct," Clinical Chemistry, vol. 33, no. 2, pp. 214-220, 1987.

[28] R. L. Levine, D. Garland, C. N. Oliver et al., "Determination of carbonyl content in oxidatively modified proteins," Methods in Enzymology, vol. 186, pp. 464-478, 1990.

[29] M. S. Moron, J. W. Depierre, and B. Mannervik, "Levels of glutathione, glutathione reductase and glutathione S-transferase activities in rat lung and liver," Biochimica et Biophysica Acta, vol. 582, no. 1, pp. 67-78, 1979.

[30] H. E. Aebi, "Enzymes I: oxidoreductases, transferases," in Methods of Enzymatic Analysis, H. U. Bergmeyer, Ed., pp. 273285, VCH, Weinheim, Germany, 1987.

[31] A. L. Baker and N. E. Tolbert, "Glycolate oxidase (ferredoxincontaining form)," Methods in Enzymology, vol. 9, pp. 338-342, 1966.

[32] J. King, in Practical Clinical Enzymology, vol. 87, van Nostrand, 1965.

[33] S. R. Khan, "Calcium oxalate crystal interaction with renal tubular epithelium, mechanism of crystal adhesion and its impact on stone development," Urological Research, vol. 23, no. 2, pp. 71-79, 1995.

[34] S. R. Khan and R. L. Hackett, "Retention of calcium oxalate crystals in renal tubules," Scanning Microscopy, vol. 5, pp. 707$712,1991$.

[35] F. Dal Moro, M. Mancini, I. M. Tavolini, V. de Marco, and P. Bassi, "Cellular and molecular gateways to urolithiasis: a new insight," Urologia Internationalis, vol. 74, no. 3, pp. 193-197, 2005.

[36] H. S. Huang, M. C. Ma, C. F. Chen, and J. Chen, "Lipid peroxidation and its correlations with urinary levels of oxalate, citric acid, and osteopontin in patients with renal calcium oxalate stones," Urology, vol. 62, no. 6, pp. 1123-1128, 2003.

[37] M. Santhosh Kumar and R. Selvam, "Supplementation of vitamin E and selenium prevents hyperoxaluria in experimental urolithic rats," Journal of Nutritional Biochemistry, vol. 14, no. 6, pp. 306-313, 2003.

[38] S. Thamilselvan and M. Menon, "Vitamin E therapy prevents hyperoxaluria-induced calcium oxalate crystal deposition in the kidney by improving renal tissue antioxidant status," British Journal of Urology International, vol. 96, no. 1, pp. 117-126, 2005.

[39] Y. Itoh, T. Yasui, A. Okada, K. Tozawa, Y. Hayashi, and K. Kohri, "Preventive effects of green tea on renal stone formation and the role of oxidative stress in nephrolithiasis," Journal of Urology, vol. 173, no. 1, pp. 271-275, 2005.

[40] S. Thamilselvan, R. L. Hackett, and S. R. Khan, "Lipid peroxidation in ethylene glycol induced hyperoxaluria and calcium oxalate nephrolithiasis," Journal of Urology, vol. 157, no. 3, pp. 1059-1063, 1997.

[41] C. H. Tsai, Y. C. Chen, L. D. Chen et al., "A traditional Chinese herbal antilithic formula, Wulingsan, effectively prevents the renal deposition of calcium oxalate crystal in ethylene glycolfed rats," Urological Research, vol. 36, no. 1, pp. 17-24, 2008.

[42] J. Fan, M. A. Glass, and P. S. Chandhoke, "Impact of ammonium chloride administration on rat ethylene glycol urolithiasis model," Scanning Microscopy, vol. 13, pp. 299-306, 1999.
[43] H. K. Park, B. C. Jeong, M. K. Sung et al., "Reduction of oxidative stress in cultured renal tubular cells and preventive effects on renal stone formation by the bioflavonoid Quercetin," Journal of Urology, vol. 179, no. 4, pp. 1620-1626, 2008. 


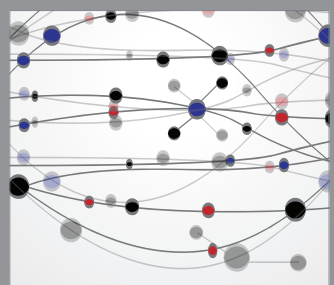

The Scientific World Journal
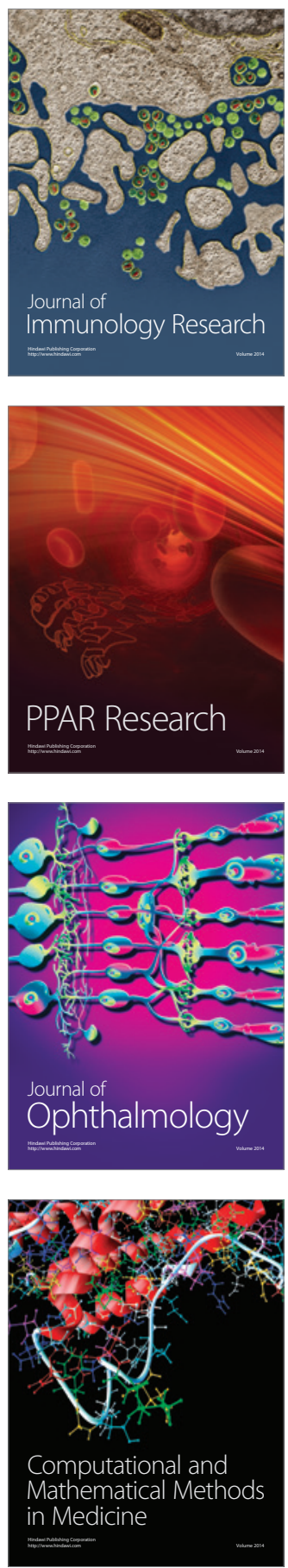

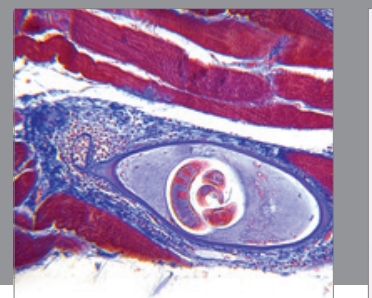

Gastroenterology

Research and Practice
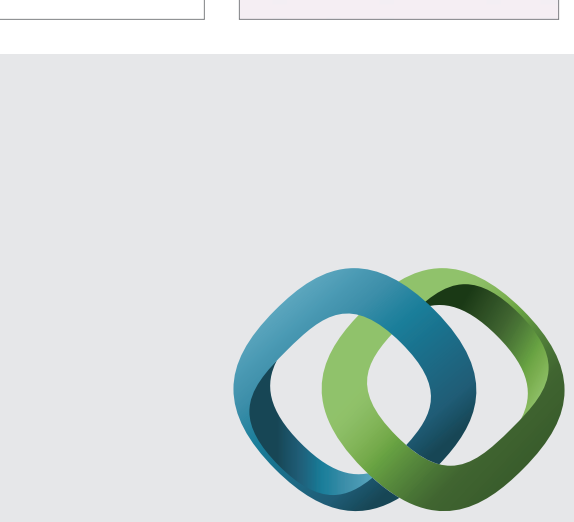

\section{Hindawi}

Submit your manuscripts at

http://www.hindawi.com
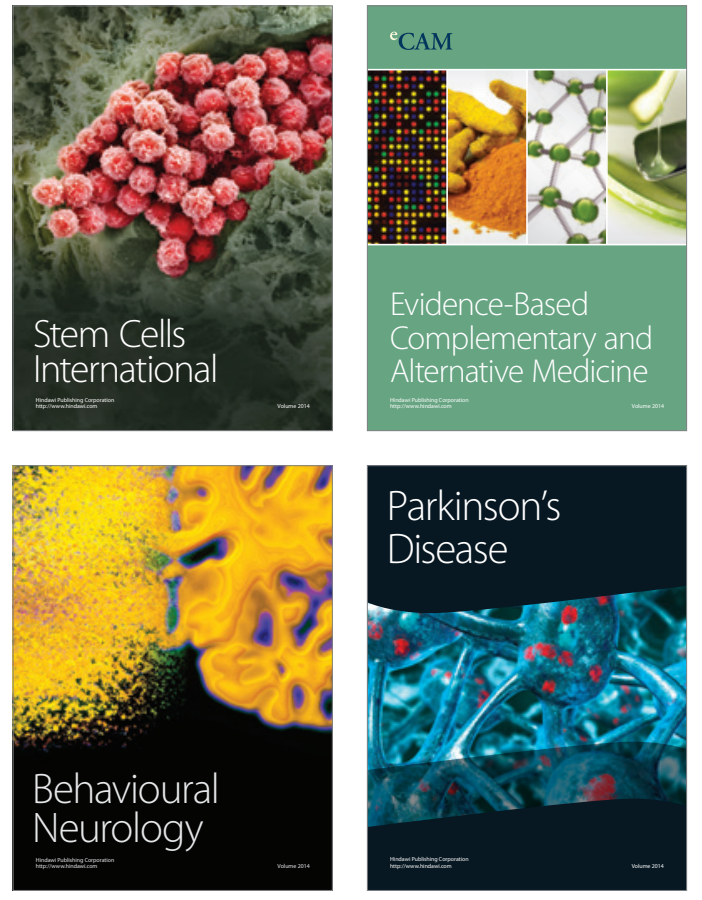
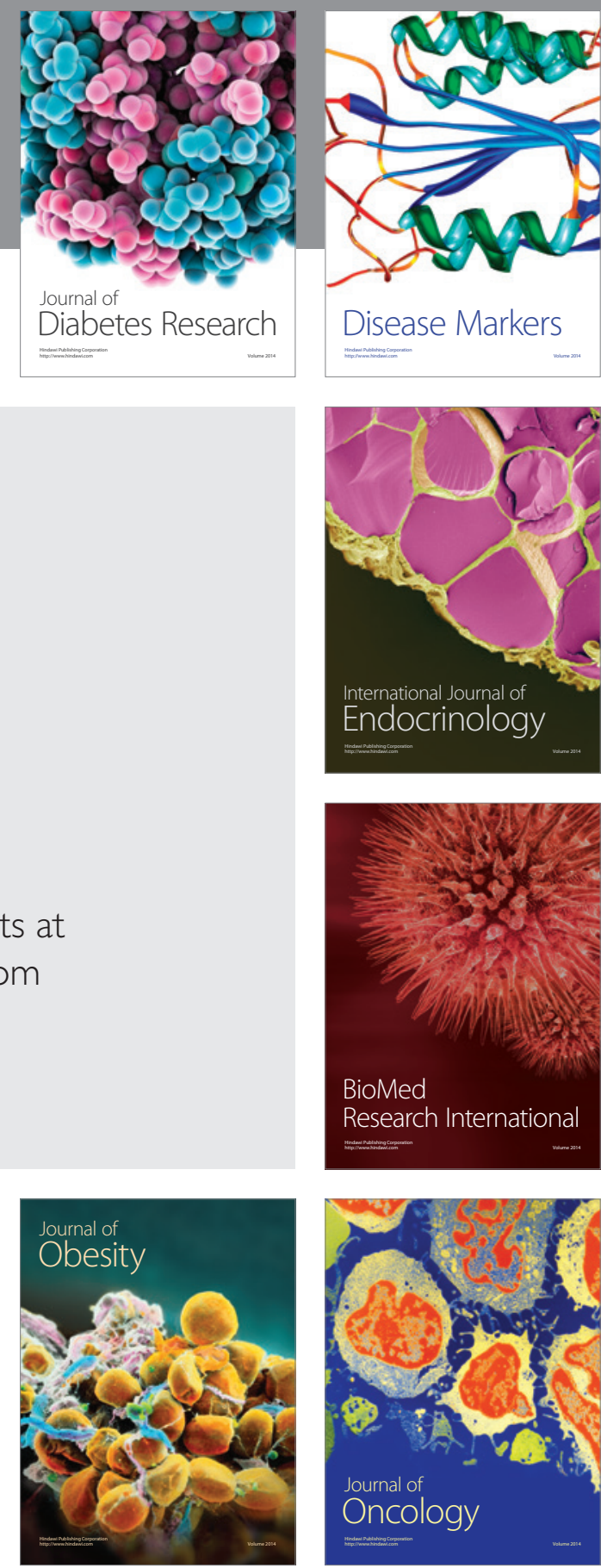

Disease Markers
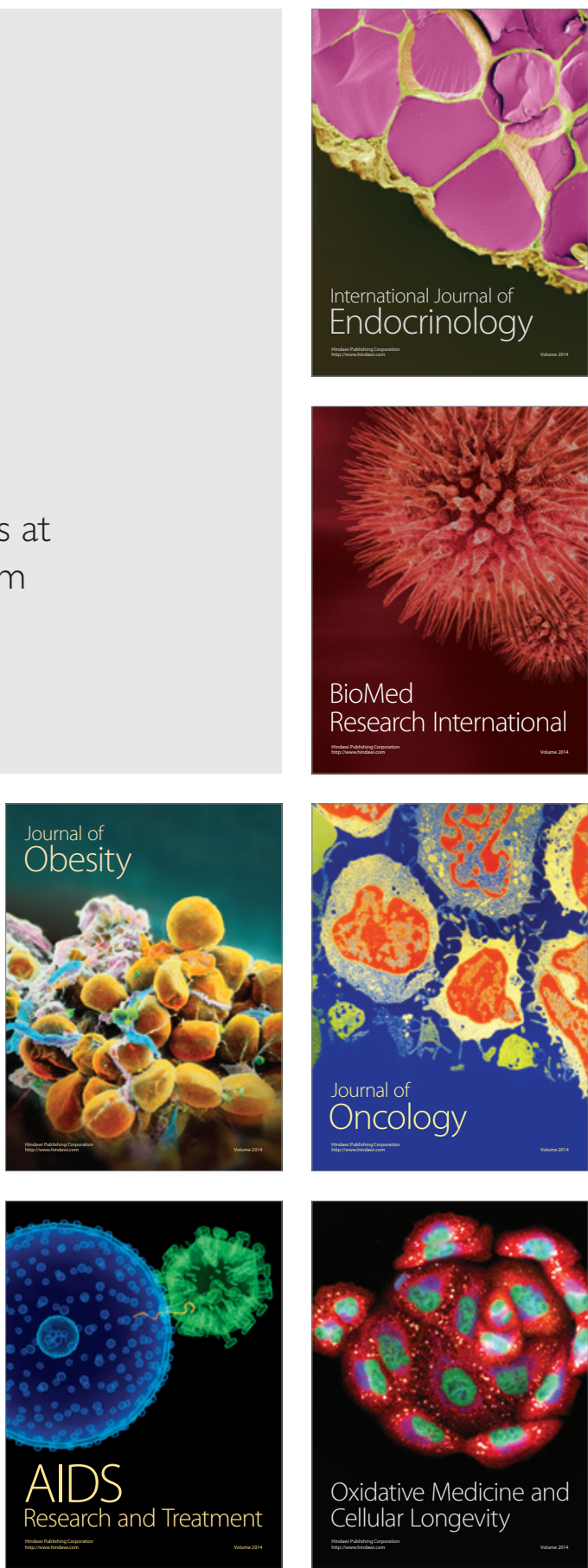